IMECE2007-41907

\title{
Gas Heater Availability Analysis and Consideration of Replacement Gas Heaters by Inline Heaters in the Pressure Reducing Stations of Natural Gas
}

\author{
H. Shokouhmand \\ School of mechanical engineering \\ University of Tehran, Iran \\ hshokoh@ut.ac.ir
}

\author{
M. Rezaei Barmi \\ School of mechanical engineering \\ University of Tehran, Iran \\ mrezaeibarmi@ut.ac.ir
}

\author{
B. Tavakoli \\ School of mechanical engineering \\ University of Shiraz, Iran \\ btavakoli80@yahoo.com
}

\begin{abstract}
Natural gas is transferred in high pressure by piping system from refiners to city gate stations. For public consumption the gas pressure is reduced in gas pressure reducing stations. The pressure is reduced in regulators and leads to a sudden drop of temperature and consequently the formation of gas hydrates. Preventing hydrate formation, natural gas is heated by passing through water bath gas heaters. In this study, the thermodynamic efficiencies of water bath gas heaters were conducted.

The effect of air-fuel ratio and the flow rate of the fuel on the efficiency of this instrument were studied. Also, the variations of efficiencies versus flame temperature have been considered and the optimum points in each state were obtained. From these comparisons, it can be concluded that, first law efficiency is suitable meanwhile second law efficiency is very low. The main reason of low second law efficiency is that high availability generation by fuel causes low enhancement in the availability of natural gas, passed through heaters. Also, one dimensional simulation has been employed to compute temperature distribution numerically in whole of a gas pressure reducing station with water bath gas heaters and with shell and tube heaters (inline heaters). Comparison between these two stations show that the gas pressure reducing station with inline heaters is more appropriate than the one with water bath gas heaters.

Finally, water bath gas heaters and inline heaters have been studied economically by utilizing energy flow optimization
\end{abstract}

model, EFOM. It is shown that the inline heaters have less cost of heat generation and they are more economical.

\section{INTRODUCTION}

The pressure of natural gas is reduced in entrance of gas distribution lines of cities at city gate stations, CGS. The pressure reduction may cause hydrate phenomenon and lead to pipe obstacle which is too dangerous. Preventing the hydrate formation, the water bath gas heaters are employed in many city gate stations to raise the gas temperature before the pressure reduction occurs in regulators.

Gas hydrates are crystalline compounds that are formed physically stable interaction between water and relatively small guest molecules occupied in the cavities built by water molecules [1, 2]. Natural gas is always in company with water and if its transportation does not perform in appropriate conditions then hydrate formation would be inevitable [14].

The pressure and temperature are the most effective parameters on hydrate formation. The standard temperature of natural gas is $15^{\circ} \mathrm{C}$ in gas distribution pipelines. As gas pressure decreases from $7 \mathrm{MPa}$ to $1.7 \mathrm{MPa}$ by regulators at pressure reducing stations, the temperature decreases as well. Generally gas temperature decreases about $0.5^{\circ} \mathrm{C}$ in each 100 $\mathrm{kPa}$ pressure drop which is obtained from constant enthalpy process during pressure reducing of natural gas in the regulators.

As it is shown in Figure 1, the aspects of water gas bath heaters contain shell, gas coils, combustion chamber, fire tube, expansion tank, exhaust and fuel supply. Natural gas would be 
heated by passing through the coils plunging in hot water stored in expansion tank. The water is stationary in the tank and it is heated by the fire tube, then hot water heats the gas coils by free convection.

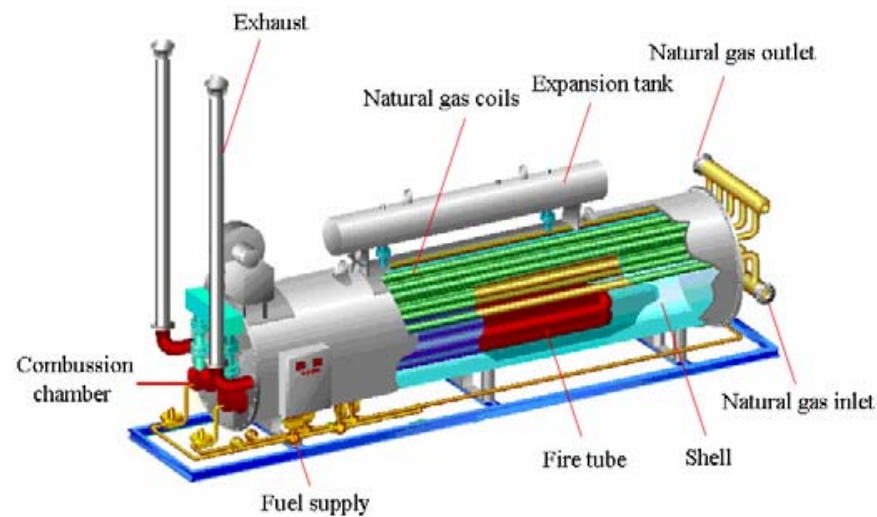

Figure 1- Water bath gas heater elements

The consuming natural gas includes the hydrocarbons of $85 \%$ methane $\left(\mathrm{CH}_{4}\right)$ and $15 \%$ the combination of ethane $\left(\mathrm{C}_{2} \mathrm{H}_{6}\right)$, propane $\left(\mathrm{C}_{3} \mathrm{H}_{8}\right)$ and butane $\left(\mathrm{C}_{4} \mathrm{H}_{10}\right)$. Thus the properties of natural gas are assumed to be similar to the properties of methane in this study [10, 11 , and 12$]$.

The second law efficiency of the aspects of the heater including combustion chamber, water tank and gas coils versus the excess air, adiabatic flame temperature and fuel flow rate are computed. The thermal efficiency of the total package of heater is then compared with its second-law of thermodynamics efficiency.

Besides, to consider the effects of gas heaters and inline heaters on energy consumption in the station, one dimensional simulation of heat transfer is applied for both types of heaters. Then economical consideration is used to compare these heaters.

\section{NOMENCLATURE}

\begin{tabular}{|llc|}
\hline$L$ & Pipe length & $m$ \\
$A$ & Perimeter surface area & $m^{2}$ \\
$R_{i n}$ & Pipe inside diameter & $m$ \\
$t$ & Pipe thickness & $m$ \\
$n$ & Number of cells & - \\
\hline$E$ & Energy & $W$ \\
$\dot{E}_{W}$ & Exergy availability & $\mathrm{W} / \mathrm{kg}$ \\
$q$ & Heat transfer & $\mathrm{W}$ \\
$Q$ & Heat transfer & $\mathrm{J}$ \\
$H$ & Enthalpy & $\mathrm{J} / \mathrm{kg}$ \\
$W$ & Work & $\mathrm{J}$ \\
$T$ & Temperature & $\mathrm{K}$ \\
$h$ & Convective heat transfer coefficient & $\mathrm{W} / \mathrm{m}^{2} . K$ \\
\hline
\end{tabular}

\begin{tabular}{|c|c|c|}
\hline$S$ & Entropy & $J / K$ \\
\hline$S$ & Specific entropy & $\mathrm{J} / \mathrm{kg} \cdot \mathrm{K}$ \\
\hline$\dot{m}$ & Mass flow rate & $\mathrm{kg} / \mathrm{s}$ \\
\hline$v$ & Velocity & $\mathrm{m} / \mathrm{s}$ \\
\hline$R$ & Thermal resistance & $K / W$ \\
\hline$k$ & Thermal conductivity & $W / m . K$ \\
\hline$c_{p}$ & Specific heat & $\mathrm{kJ} / \mathrm{kg} . \mathrm{K}$ \\
\hline$g$ & Gravitational acceleration & $\mathrm{m} / \mathrm{s}^{2}$ \\
\hline $\operatorname{Re}$ & Reynolds number & - \\
\hline $\operatorname{Pr}$ & Prandtl number & - \\
\hline $\mathrm{Nu}$ & Nusselt Number & - \\
\hline \multicolumn{3}{|c|}{ Subscripts } \\
\hline conv & Convection & - \\
\hline$f$ & Fuel & - \\
\hline$p$ & Combustion product & - \\
\hline$R$ & Combustion reaction & \\
\hline$m$ & Mean value & - \\
\hline si & Inside surface & - \\
\hline$s$ & Surface & - \\
\hline so & Outside surface & - \\
\hline$i$ & Inlet & - \\
\hline$e$ & Outlet & - \\
\hline in & Inside & - \\
\hline out & Outside & - \\
\hline gen & Generation & - \\
\hline 0 & Neutral state & - \\
\hline env & Environment & - \\
\hline
\end{tabular}

\section{GAS HEATER AVAILABILITY ANALYSIS}

\section{GOVERNING EQUATIONS}

Employing the first law of thermodynamics, the temperature, heat transfer and efficiencies of different parts of this kind of heaters are calculated.

It is possible that one part has the maximum energy losses while another part has the maximum availability losses.

Assuming a steady-state, steady-flow process the first and second laws of thermodynamics are as follows. The first law of thermodynamics for a control volume is,

$$
\begin{aligned}
& \sum \dot{m}\left(H+\frac{1}{2} v^{2}+g z\right)_{i}-\sum \dot{m}\left(H+\frac{1}{2} v^{2}+g z\right)_{e} \\
& +\dot{Q}-\dot{W}_{s h}=\frac{\partial E}{\partial t}
\end{aligned}
$$

Where, the dot over the letters show the rate of that parameter, the subscripts of $i$ and e represent the inlet and exit situations of the control volume respectively. $\dot{m}, H, v, g, Q, W$, $E$, are mass flow rate, enthalpy, velocity, gravitational acceleration, heat, work and the total energy of the control volume respectively. 
Defining the entropy generation, $\dot{S}_{\text {gen }}$, the second law of thermodynamics is,

$$
\sum \dot{m}_{i} \dot{s}_{i}-\sum \dot{m}_{e} \dot{s}_{e}+\sum \frac{\dot{Q}_{c . v .}}{T}-\dot{S}_{g e n}=\frac{d S_{c . v .}}{d t}
$$

Combining the first and second laws of thermodynamics, the availability or exergy equation is obtained as [6, 7],

$$
\begin{aligned}
\dot{E}_{W}= & -\frac{d}{d t}\left(E+P_{0} v_{0}\right)+\sum\left(1-\frac{T_{0}}{T i}\right) Q_{0} \\
& +\sum_{\text {in }} \dot{m}\left(H_{0}-T_{0} s\right)-\sum_{\text {out }} \dot{m}\left(H_{0}-T_{0} s\right)-T_{0} \dot{S}_{\text {gen }}
\end{aligned}
$$

Where, $\dot{E}_{W}$ is the availability or exergy. First expression on the right side of Eq. (3) indicates the rate of change of stationary exergy, second expression shows the rate of exergy transfer by heat transfer with conduction, third and fourth ones are the entering and exiting exergies respectively and the last one is the exergy production term. $T_{1}$ is the temperature of the interfaces between the regions of heat transfer and $\mathrm{T}_{0}$ is the temperature of ambient air assumed to be $25^{\circ} \mathrm{C}$.

All thermal processes are assumed to perform in steady state conditions thus the term of stationary exergy can be negligible.

Because of the chemical reactions in fire tube, the enthalpy of formation is necessary to be used in energy equation. The combustion equation of methane is,

$\mathrm{CH}_{4}+2 n\left(\mathrm{O}_{2}+3.76 \mathrm{~N}_{2}\right) \rightarrow \mathrm{CO}_{2}+2 \mathrm{H}_{2} \mathrm{O}+2(n-1) \mathrm{O}_{2}+7.25 n N_{2}$

Where $\mathrm{N}$ is nitrogen and $\mathrm{n}$ is the fuel-air ratio on a mass basis, $n=\frac{m_{\text {air }}}{m_{\text {fuel }}}$. Assuming the combustion process takes place adiabatically without any changes in kinetic or potential energy, the temperature of the products is referred to as the adiabatic flame temperature [1].

The adiabatic flame temperature can be obtained from the equilibrium of reactants' enthalpy with products' enthalpy when complete combustion occurs,

$$
\begin{gathered}
H_{R}=H_{P} \\
H_{R}=\left(\dot{m}_{f} H_{f}^{0}\right)_{\text {fuel }} \\
H_{p}=\sum \dot{m}\left(H_{P}^{0}+\Delta H_{P}\right)
\end{gathered}
$$

Considering the fuel-air ratio as an input of the problem the adiabatic flame temperature can be computed by a trial and error process.

The first and second law efficiencies are,

$$
\eta_{\mathrm{I}}=\frac{\text { Energy }_{\text {out }}}{\text { Energy }_{\text {in }}}
$$

$$
\eta_{\Pi}=\frac{\text { Exergy }_{\text {out }}}{\text { Exergy }_{\text {in }}}
$$

\section{EFFICIENCY ANALYSES OF DIFFERENT PARTS OF HEATER}

\section{COMBUSTION CHAMBER}

The combustion chamber is considered as the first control volume computed its optimum second-law efficiency. Pressure is assumed to be constant during the combustion. Employing energy equilibrium the rate of heat generation follows as,

$$
\sum \dot{m}_{p} H_{p}-\sum \dot{m}_{f} H_{f}=\dot{Q}_{1}
$$

Where, $\dot{Q}_{1}$ is the heat transferred from combustion chamber to water storage in the tank. The useful exergy is the part exited from the control volume and located at interface of combustion chamber and water tank,

$$
\dot{E}_{\text {useful }}=\dot{Q}_{1}\left(1-\frac{T_{0}}{T_{1 \text { lave }}}\right)
$$

Where, $\mathrm{T}_{1 \text { ave }}$ is the mean temperature between water temperature and flame temperature. The second-law efficiency of the control volume of combustion chamber is,

$$
\begin{gathered}
\eta_{\Pi}=\frac{\dot{E}_{u s e f u l}}{\dot{E}_{i n, p}} \\
\dot{E}_{i n, p}=\sum \dot{m}_{p} \dot{e}_{p}
\end{gathered}
$$

The difference between the availability of the combustion products at adiabatic flame temperature and at outlet temperature in exhaust is considered as the inlet exergy of this control volume.

$$
\begin{aligned}
& \dot{E}_{i n, p}= \\
& \dot{m}_{C O_{2}}\left\{\left[h_{a d} T_{a d}-h_{e x} T_{e x}\right]-T_{0}\left[s_{a d} T_{a d}-s_{e x} T_{e x}\right]\right\}_{C O_{2}}+ \\
& \dot{m}_{H_{2} O}\left\{\left[h_{a d} T_{a d}-h_{e x} T_{e x}\right]-T_{0}\left[s_{a d} T_{a d}-s_{e x} T_{e x}\right]\right\}_{H_{2} O}+ \\
& \dot{m}_{\mathrm{O}_{2}}\left\{\left[h_{a d} T_{a d}-h_{e x} T_{e x}\right]-T_{0}\left[s_{a d} T_{a d}-s_{e x} T_{e x}\right]\right\}_{O_{2}}+ \\
& \dot{m}_{N_{2}}\left\{\left[h_{a d} T_{a d}-h_{e x} T_{e x}\right]-T_{0}\left[s_{a d} T_{a d}-s_{e x} T_{e x}\right]\right\}_{N_{2}}
\end{aligned}
$$

\section{WATER TANK}

Water storage in tank is considered as a control volume that the total heat transferred from combustion chamber is stored in that leading a constant water temperature. The hot water is responsible to heat the gas passing the plugged coils.

Although the heat transfer to the storage water is assumed to be ideal with no lost of energy, a large part of availability is lost by storage water. 
The second-law efficiency for the control volume of water storage is computed as,

$$
\eta_{\Pi}=\frac{\left(1-\frac{T_{0}}{T_{1 a v e}}\right)}{\left(1-\frac{T_{0}}{T_{2 a v e}}\right)}
$$

Where, $T_{2 a v e}$ is the mean temperature between water temperature and gas temperature passing through the coils. As $T_{1 a v e}$ is much greater than $T_{2 a v e}$, it is expected that the secondlaw efficiency of this control volume be extremely low.

\section{NATURAL GAS COILS}

The third control volume is the coils which natural gas passes through them. The inlet and outlet temperatures of natural gas in the coils are fixed as $4^{\circ} \mathrm{C}$ and $38^{\circ} \mathrm{C}$ respectively. The heat transfer occurs with constant gas pressure of 6.89 MPa through the coils.

Energy equation of this control volume is

$$
\dot{m}_{o} h_{o}-\dot{m}_{i} h_{i}=\dot{Q}_{2}
$$

Where, the subscripts of $\mathrm{o}$ and $\mathrm{i}$ indicate the outlet and inlet mass flow rates and enthalpy rates. It is assumed that heat transfer is occurred with no lost of energy between combustion chamber and water storage and between water storage and natural gas passing through coils as well, thus $\dot{\mathrm{Q}}_{1}=\dot{\mathrm{Q}}_{2}$.

The availability difference between inlet and outlet of the gas passing the coils is, $\dot{E}_{\text {in }}-\dot{E}_{\text {out }}=\dot{m}_{\mathrm{CH}_{4}}\left\{\left[h_{\text {in }} T_{\text {in }}-h_{\text {out }} T_{\text {out }}\right]-T_{0}\left[s_{\text {in }} T_{\text {in }}-s_{\text {out }} T_{\text {out }}\right]\right\}_{\mathrm{CH}_{4}}$

Hence, the second-law efficiency of the coils control volume can be identified as,

$$
\eta_{\Pi}=\frac{\dot{E}_{\text {useful }}}{\dot{E}_{\text {in }}}
$$

Where, $\dot{\mathrm{E}}_{\text {useful }}$ is the availability increasing due to the temperature increase of gas and $\dot{\mathrm{E}}_{\mathrm{in}}$ is,

$$
\dot{E}_{\text {in }}=\dot{Q}_{2}\left(1-\frac{T_{0}}{T_{\text {2ave }}}\right)
$$

The availability increase of gas depends on enthalpy differences in inlet and outlet temperatures and it is independent of the amount of heat, transferred to the coil directly.

Although any loss of energy in processes of heat transfer from combustion chamber to the coils of gas is neglected, the amount of loss of availability is totally considerable.

\section{THE PACKAGE OF GAS HEATER}

In this part the gas heater is considered as a complete package that the natural gas with low temperature entering the gas coils together with the natural gas entering the combustion chamber create the inlet flow rates of this control volume and the heated gas exiting from the coils in company with the combustion productions leaving the exhaust create the outlet flow rates of this control volume.

The thermal efficiency of the heater is,

$$
\eta_{\mathrm{I}}=\frac{\dot{m}_{C_{H_{4}}}\left(h_{o}-h_{i}\right)}{\dot{m}_{f} L H V}
$$

Where, the nominator of the division shows the variation of enthalpy due to the increase of gas temperature and the denominator is the product of mass flow rate and latent heat value, LHV, of methane gas as the fuel of combustion chamber.

The second-law efficiency of heater is defined as the ratio of the exergy variation of natural gas passing through coils to the exergy difference between the combustion productions in chamber and exhaust.

$$
\eta_{\mathrm{I}}=\frac{\dot{E}_{\text {out }}-\dot{E}_{\text {in }}}{\sum \dot{m}_{p} \dot{e}_{p, \text { in }}}
$$

\section{NUMERICAL ANALYSIS}

The temperature and pressure of natural gas before entering the heater is $4^{\circ} \mathrm{C}$ and $6.89 \mathrm{MPa}$. The heating process of gas occurs in a constant pressure condition to prepare the gas for pressure reduction in regulators. The appropriate gas temperature for entering the regulators is $38^{\circ} \mathrm{C}$. The flow rate of natural gas to each heater is $3000 \mathrm{SCMH}$.

In these conditions the efficiencies of water bath gas heater are investigated vs. flame adiabatic temperature, mass flow rate of fuel and excess air.

According to the equations (9) and (15) the adiabatic flame temperature can be computed vs. the excess air and fuel flow rates. Using equations (17) and (18) the thermal efficiency of heater is obtained.

Figure 2 shows the second-law efficiency of heater for the flame temperature between $450^{\circ} \mathrm{C}$ and $1500^{\circ} \mathrm{C}$. Figure 2 and Figure 3 indicate the second-law efficiency of heater for different fuel-air ratios and fuel flow rates respectively. 


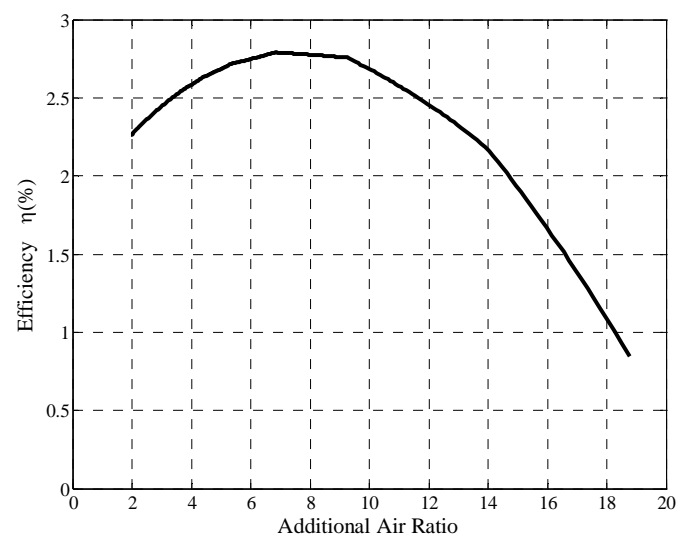

Figure 2- efficiency variation via adiabatic temperature of combustion chamber

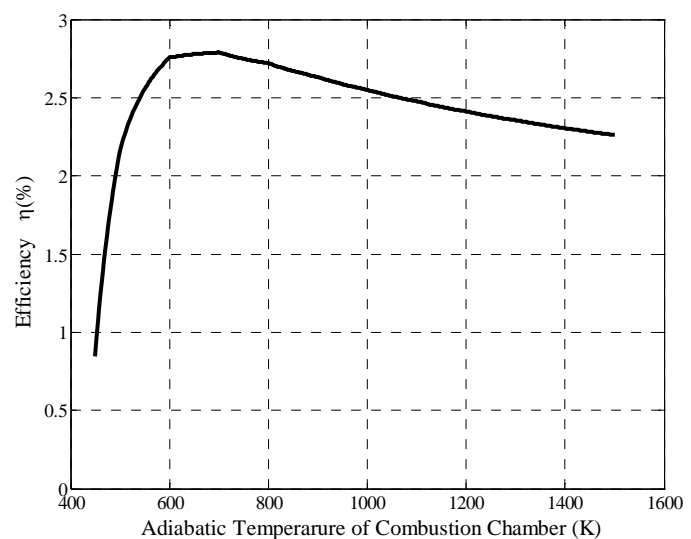

Figure 3- Efficiency variation via additional air ratio

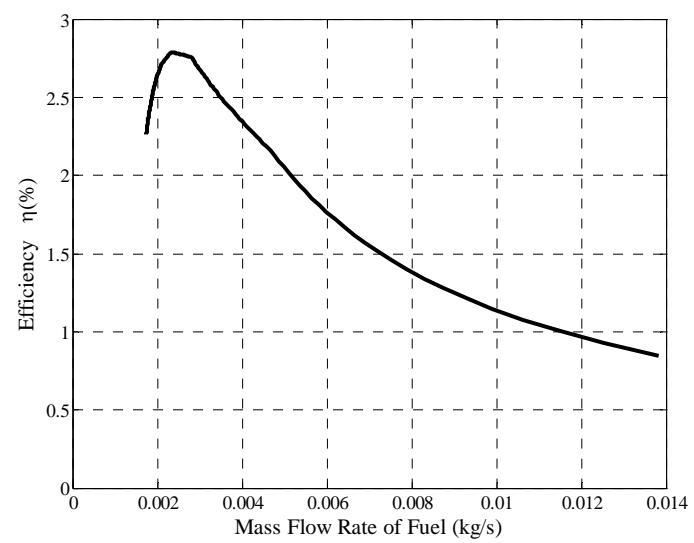

Figure 4- Efficiency variation via mass flow rate of fuel
As it is indicated in these figures the optimum temperature, fuel-air ratio and fuel flow rate for maximum availability are $700 \mathrm{~K}, 6.828$ and $0.0023 \mathrm{~kg} / \mathrm{s}$.

Using equation (18) thermal efficiency of heater for the maximum availability is $\eta_{\mathrm{I}}=56.15 \%$ at this point the highest second-law efficiency of heater appears which is calculated by equation (19) $\eta_{\Pi}=2.79 \%$. The second law efficiency of heater could be computed by multiplying the efficiencies of different parts of the instrument.

Table 1 shows the second-law efficiency of different parts of heater.

\begin{tabular}{|c|c|}
\hline Part & Efficiency \% \\
\hline Combustion chamber & 83.46 \\
\hline Water & 21.56 \\
\hline Natural gas coils & 15.15 \\
\hline Gas heater & 2.79 \\
\hline
\end{tabular}

Table 1- Efficiency of different parts of gas heater

Comparing the computed efficiencies with the ones specified on Table 2 it can be inferred that the calculated efficiencies are the same with the ones calculated previously and there is a huge gap between thermal efficiencies and second-law efficiencies.

\begin{tabular}{|c|c|c|}
\hline Use & $\eta_{I}(\%)$ & $\eta_{I I}(\%)$ \\
\hline \multicolumn{3}{|l|}{ Space Heating } \\
\hline Furnaces & 60 & 6 \\
\hline \multicolumn{3}{|l|}{ Water Heating } \\
\hline Electric & 75 & $1 \sim 2$ \\
\hline Gas & 50 & 3 \\
\hline \multicolumn{3}{|l|}{ Industrial } \\
\hline Process steam & 80 & 25 \\
\hline Direct heat & 40 & 20 \\
\hline
\end{tabular}

Table 2- Comparison between first and second thermodynamic efficiencies for different usages

PRESSURE REDUCING STATIONS OF NATURAL GAS

Considering the effects of gas heaters and inline heaters on energy consumption in pressure reducing stations, one dimensional simulation for whole of station is applied for both types of heaters. In order to pressure reducing station size and complicated piping system, two or three dimensional simulations take a lot of time and they need powerful processor; therefore, these simulations are impractical. The one dimensional simulation takes a little time and it can help to understand the amount of energy consumption, approximately.

\section{NUMERICAL SIMULATION}

To calculate the temperature and the heat transfer distribution in a pressure reducing station of natural gas, one dimensional analysis is used. 
A typical natural gas pipe is shown in Figure 5.

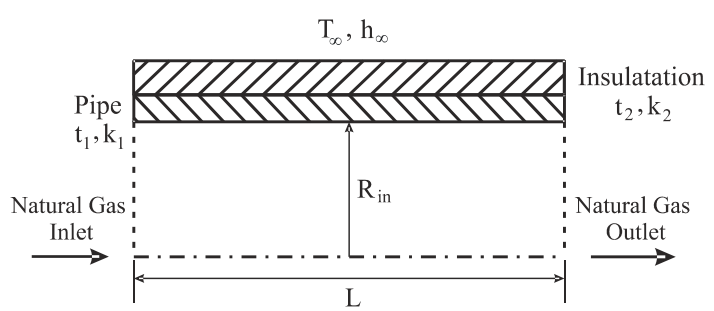

Figure 5- Natural gas pipe

The element of Figure 6 is assumed for simulation of heat transfer in a pipe.

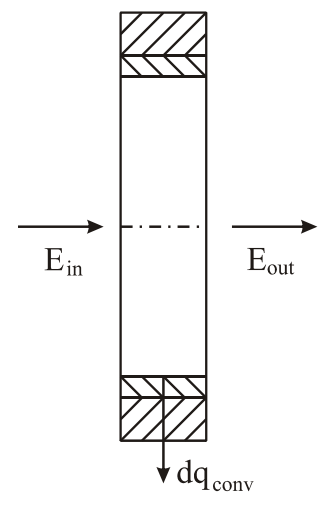

Figure 6- Typical element of the pipe

Thermal circuit of the pipe is shown in Figure 7.

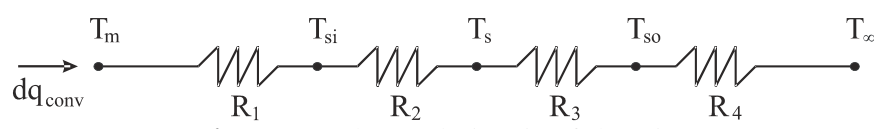

Figure 7- Thermal circuit of the pipe

Thermal resistance that are shown in Figure 7 are calculated as follows,

$$
\begin{gathered}
R_{1}=\frac{1}{h_{\text {in }} A_{\text {in }}}=\frac{1}{h_{\text {in }}\left(2 \pi R_{\text {in }} d x\right)} \\
R_{2}=\frac{\ln \frac{R_{\text {in }}+t 1}{R_{\text {in }}}}{2 \pi k_{1} d x}, R_{3}=\frac{\ln \frac{R_{\text {in }}+t_{1}+t_{2}}{R_{\text {in }}+t_{1}}}{2 \pi k_{2} d x} \\
R_{4}=\frac{1}{h_{\text {out }} A_{\text {out }}}=\frac{1}{h_{\text {out }}\left[2 \pi\left(R_{\text {in }}+t_{1}+t_{2}\right) d x\right]}
\end{gathered}
$$

For the element with length $d x$, first law of thermodynamic and heat transfer equations are,

$E_{\text {in }}-E_{\text {out }}-q_{\text {conv }}=0$

$E_{\text {in }}-E_{\text {out }}=m \cdot c_{p} \cdot\left(T_{\text {in }}-T_{\text {out }}\right)$

$$
\begin{aligned}
& q_{\text {conv }}=h_{\text {in }} \cdot A \cdot\left(T_{m}-T_{s i}\right) \\
& q_{\text {conv }}=\frac{T_{m}-T_{\infty}}{R_{\text {total }}}
\end{aligned}
$$

Where,

$R_{\text {total }}=R_{1}+R_{2}+R_{3}+R_{4}$

The pipe is divided to $n$ parts that are shown in Figure 8.

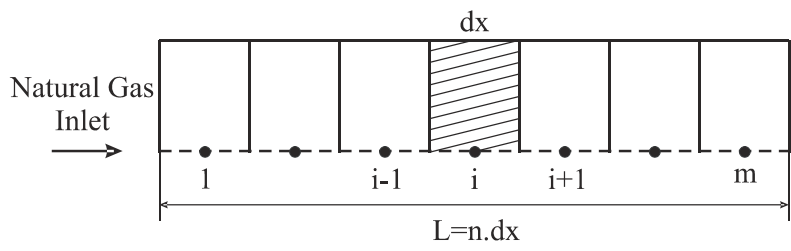

Figure 8- Grid

Therefore, the following equations must be solved in the domain to find temperature and heat transfer distribution in the pressure reducing station of natural gas.

$$
\begin{aligned}
& q_{\text {convi }}=m \cdot c_{p} \cdot\left(T_{i-1}-T_{i}\right) \\
& q_{\text {convi }}=h_{i n} \cdot A_{i n} \cdot\left(T_{s i}-T_{i}\right)=h_{i n} \cdot\left(2 \pi R_{i n} d x\right)\left(T_{i}-T_{s i}\right) \\
& q_{\text {convi }}=\frac{T_{i}-T_{\infty}}{R_{\text {total }}}
\end{aligned}
$$

Finally, the following system of equations must be solved for the whole station,

$$
\left[\begin{array}{ccc}
1 & m \cdot c_{p} & 0 \\
1 & -2 \pi R_{\text {in }} h_{\text {in }} d x & 2 \pi R_{\text {in }} h_{\text {in }} d x \\
R_{\text {total }} & -1 & 0
\end{array}\right]\left[\begin{array}{c}
q_{\text {convi }} \\
T_{i} \\
T_{s i}
\end{array}\right]=\left[\begin{array}{c}
m \cdot c_{p} T_{i-1} \\
0 \\
-T_{\infty}
\end{array}\right]
$$

Where, inside convective heat transfer coefficient, $h_{i n}$ and outside convective heat transfer coefficient, $h_{\text {out }}$ are calculated by Dittus-Bulter equation and Hilpert correlation, respectively $[1,8]$.

\section{RESULTS AND DISSCUSSION}

\section{A STATION WITH GAS HEATERS}

A typical station with gas heaters is depicted in Figure 9. This station is similar to the pressure reducing station in the Uromieh, a city in northwest of Iran, that uses three gas heaters with 300,000 SCMH capacity of natural gas transport. 


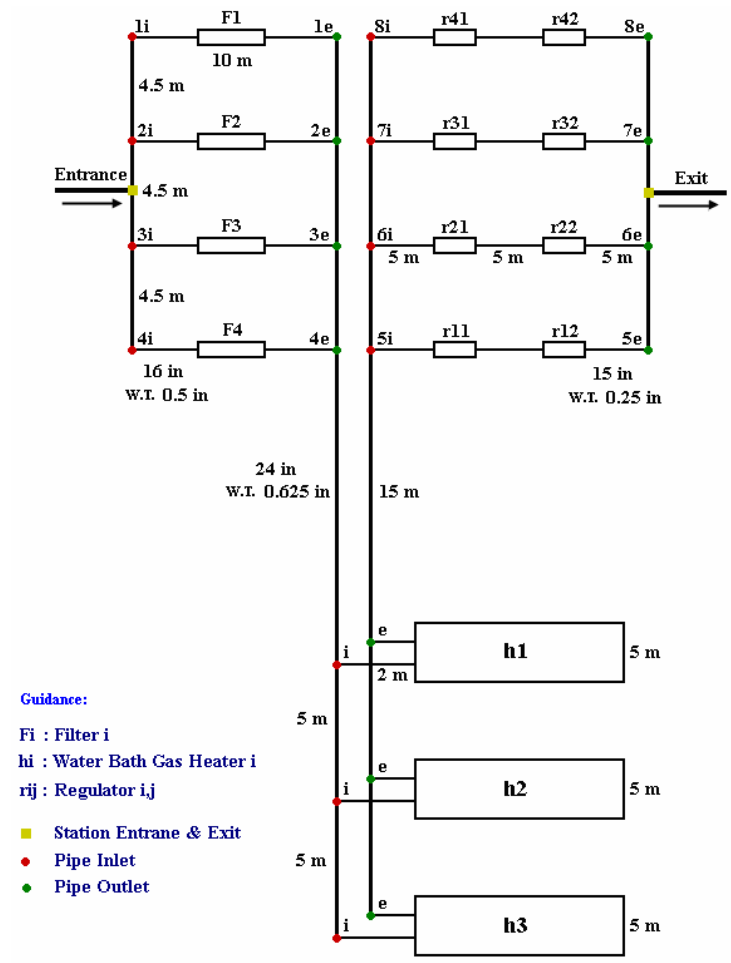

Figure 9- Pressure reducing station with gas heaters

Temperature and heat transfer distribution is computed by using one dimensional simulation for two cases of environmental temperature $T_{e n v}=25^{\circ} \mathrm{C},-5^{\circ} \mathrm{C}$. The results are presented in Table 3.

\begin{tabular}{|l|c|c|c|}
\hline Variable & $T_{e n v}=25^{\circ} \mathrm{C}$ & $T_{\text {env }}=-5^{\circ} \mathrm{C}$ & Unit \\
\hline Station capacity & 300000 & 300000 & $\mathrm{SCMH}$ \\
\hline Inlet pressure & 600 & 600 & $\mathrm{psig}$ \\
\hline Outlet pressure & 250 & 250 & $\mathrm{psig}$ \\
\hline Inlet temperature & 280 & 280 & $\mathrm{~K}$ \\
\hline Outlet temperature & 287.4339 & 286.2112 & $\mathrm{~K}$ \\
\hline $\begin{array}{l}\text { Heat transfer via } \\
\text { environment to NG }\end{array}$ & $-6.4512 \times 10^{4}$ & $+1.4847 \times 10^{5}$ & $\mathrm{~W}$ \\
\hline $\begin{array}{l}\text { heat transfer via gas } \\
\text { heaters to NG }\end{array}$ & $-2.5850 \times 10^{6}$ & $-2.5836 \times 10^{6}$ & $\mathrm{~W}$ \\
\hline $\begin{array}{l}\text { Total heat transfer } \\
\text { to NG }\end{array}$ & $-2.6495 \times 10^{6}$ & $-2.4352 \times 10^{6}$ & $\mathrm{~W}$ \\
\hline
\end{tabular}

Table 3- Results of simulation

for Pressure reducing station with gas heaters

Also, temperature distributions for the longest direction in station are shown graphically in figures (10) and (11).

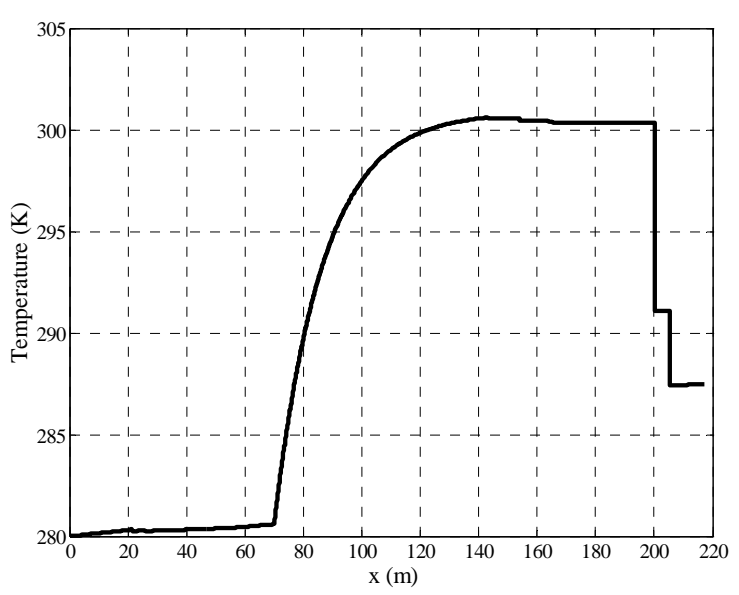

Figure 10- Temperature distribution

for pressure reducing station with gas heaters in $T_{\text {env }}=25^{\circ} \mathrm{C}$

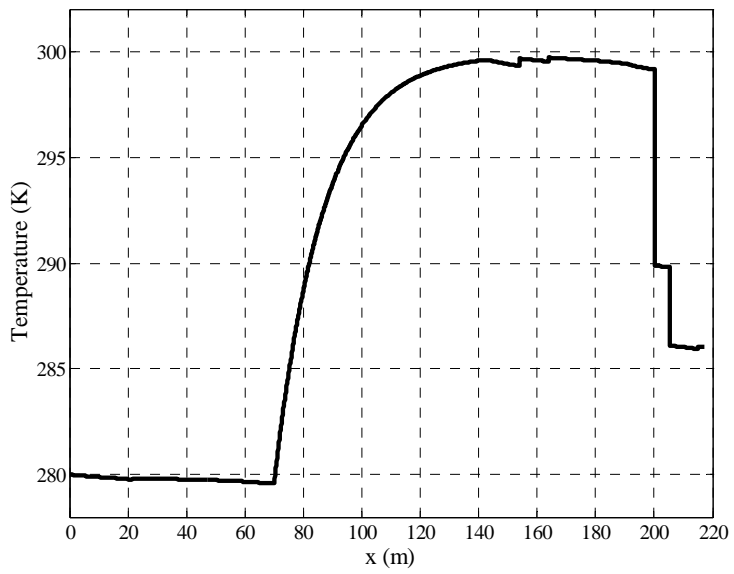

Figure 11- Temperature distribution

for pressure reducing station with gas heaters in $T_{\text {env }}=-5^{\circ} \mathrm{C}$

\section{A STATION WITH INLINE HEATERS}

A typical station with inline heaters is shown in Figure 12. In this type of stations, gas heaters are replaced by shell and tube heat exchangers. These heaters warm up natural gas with hot water that is supplied by boilers which are placed further in the station. Collection of shell and tube heat exchanger and hot water boilers is called inline heaters system.

Safety is the most important factor that makes the utilization of these heaters arrangements. To prevent the accidents such as conflagration hot water is prepared in boilers away from heat exchangers and fire tubes move away from natural gas pipes. Thus, water works in the closed circuit and pipe lines of natural gas becomes shorter as well. 


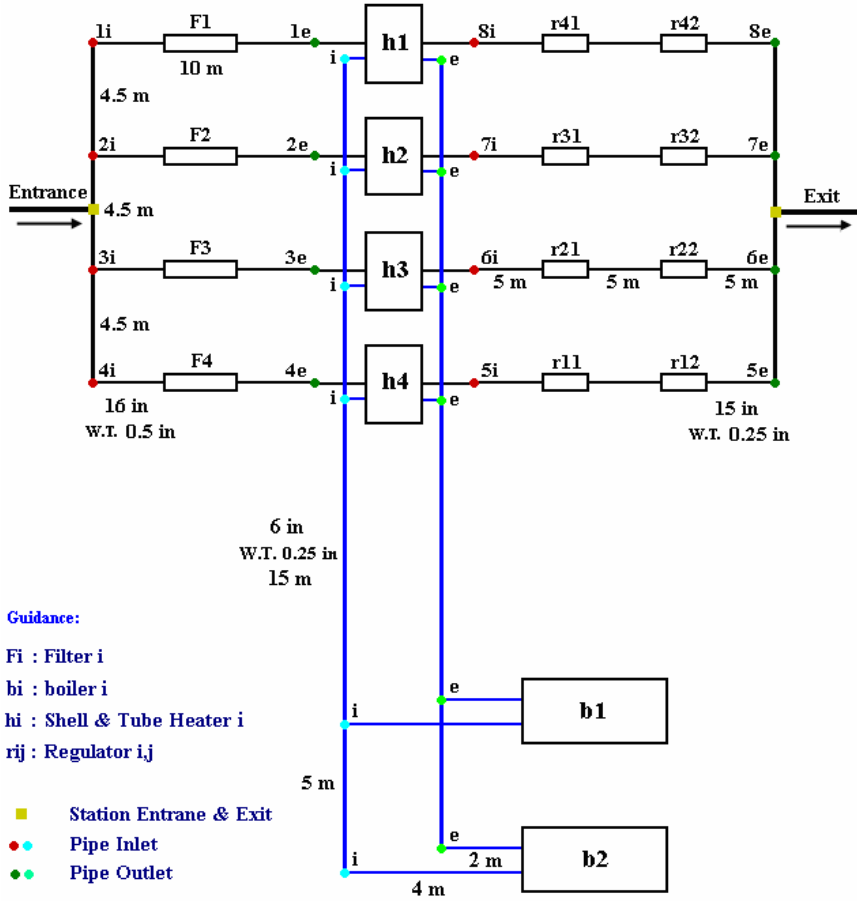

Figure 12- Pressure reducing station with inline heaters and boilers

Temperature and heat transfer distribution is computed by using one dimensional simulation for two cases of environmental temperature $T_{e n v}=25^{\circ} \mathrm{C}$ and $-5^{\circ} \mathrm{C}$. The results are presented in Table 4.

\begin{tabular}{|l|c|c|c|}
\hline Variable & $T_{e n v}=25^{\circ} \mathrm{C}$ & $T_{e n v}=-5^{\circ} \mathrm{C}$ & Unit \\
\hline Station capacity & 300000 & 300000 & $\mathrm{SCMH}$ \\
\hline Inlet pressure & 600 & 600 & $\mathrm{psig}$ \\
\hline Outlet pressure & 250 & 250 & $\mathrm{psig}$ \\
\hline Inlet temperature & 280 & 280 & $\mathrm{~K}$ \\
\hline $\begin{array}{l}\text { Outlet } \\
\text { temperature }\end{array}$ & 287.2701 & 286.4043 & $\mathrm{~K}$ \\
\hline $\begin{array}{l}\text { Heat transfer via } \\
\text { environment to NG }\end{array}$ & $-4.0103 \times 10^{4}$ & $+6.4812 \times 10^{4}$ & $\mathrm{~W}$ \\
\hline $\begin{array}{l}\text { heat transfer via gas } \\
\text { heaters to NG }\end{array}$ & $-2.5849 \times 10^{6}$ & $-2.5837 \times 10^{6}$ & $\mathrm{~W}$ \\
\hline $\begin{array}{l}\text { Total heat transfer } \\
\text { to NG }\end{array}$ & $-2.6250 \times 10^{6}$ & $-2.5189 \times 10^{6}$ & $\mathrm{~W}$ \\
\hline
\end{tabular}

Table 4- Results of simulation

for Pressure reducing station with inline heaters

Also, temperature distributions for the longest direction in station are shown graphically in the figures (13) and (14).

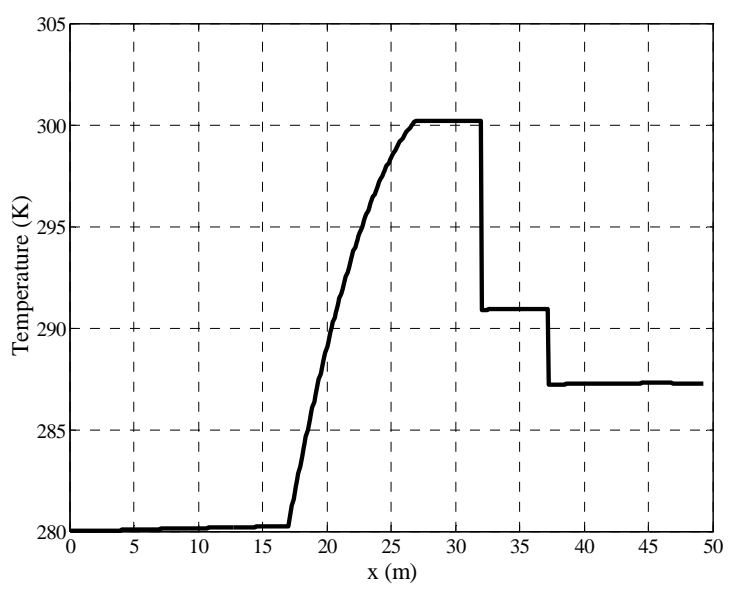

Figure 13- Temperature distribution

for pressure reducing station with inline heater in $T_{\text {env }}=25^{\circ} \mathrm{C}$

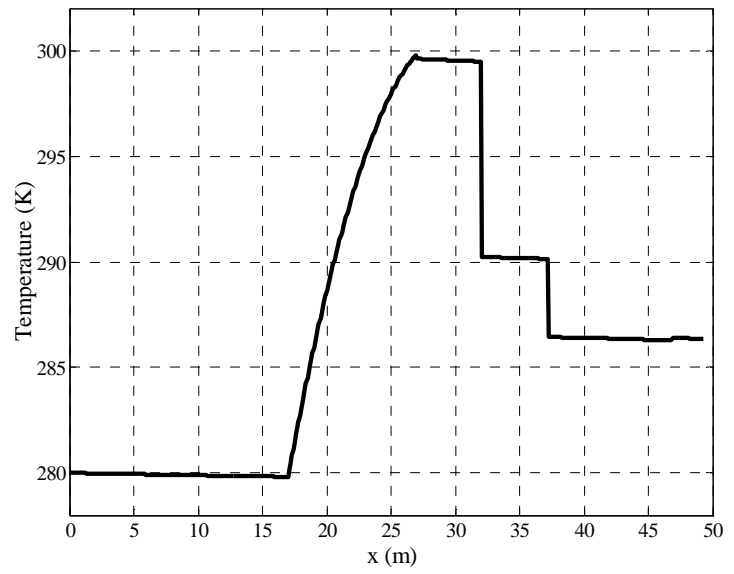

Figure 14- Temperature distribution

for pressure reducing station with inline heater in $T_{e n v}=-5^{\circ} \mathrm{C}$

In shell and tube heat exchanger, hot water warms up natural gas to prevent hydrate formation through pressure reduction in regulators. Hot water is produced in water boilers. In the outlet of boiler, water with temperature about $70^{\circ} \mathrm{C}$ exits and in the inlet of boiler, cool water that circulate in the heat exchanger, enters the boiler with the temperature about $45^{\circ} \mathrm{C}$.

Temperature and heat transfer distribution is computed by using one dimensional simulation for two cases of environmental temperature $T_{e n v}=25^{\circ} \mathrm{C}$ and $-5^{\circ} \mathrm{C}$. The results are as follows. 


\begin{tabular}{|l|c|c|c|}
\hline Variable & $T_{e n v}=25^{\circ} \mathrm{C}$ & $T_{e n v}=-5^{\circ} \mathrm{C}$ & Unit \\
\hline Inlet temperature & 323.3813 & 322.8295 & $\mathrm{~K}$ \\
\hline $\begin{array}{l}\text { Outlet } \\
\text { temperature }\end{array}$ & 344 & 344 & $\mathrm{~K}$ \\
\hline $\begin{array}{l}\text { Heat transfer via } \\
\text { environment from } \\
\text { water }\end{array}$ & $+3.2264 \times 10^{4}$ & $+6.1081 \times 10^{4}$ & $\mathrm{~W}$ \\
\hline $\begin{array}{l}\text { heat transfer via gas } \\
\text { heaters from water }\end{array}$ & $+2.5849 \times 10^{6}$ & $+2.5837 \times 10^{6}$ & $\mathrm{~W}$ \\
\hline $\begin{array}{l}\text { Total heat transfer } \\
\text { from water }\end{array}$ & $+2.6171 \times 10^{6}$ & $+2.6448 \times 10^{6}$ & $\mathrm{~W}$ \\
\hline
\end{tabular}

Table 5- Results of simulation

for boilers in pressure reducing station with inline heaters

Also, temperature distributions for the longest direction of hot water in station are shown graphically in the following figures.

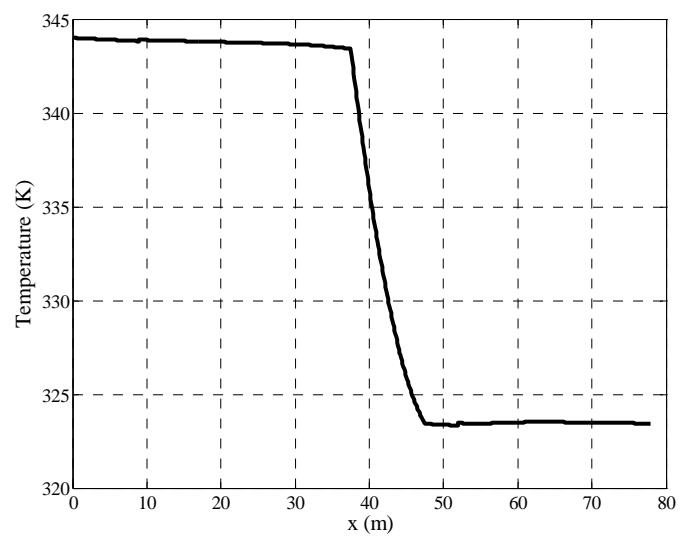

Figure 15- Temperature distribution for the longest direction of hot water in station in $T_{e n v}=25^{\circ} \mathrm{C}$

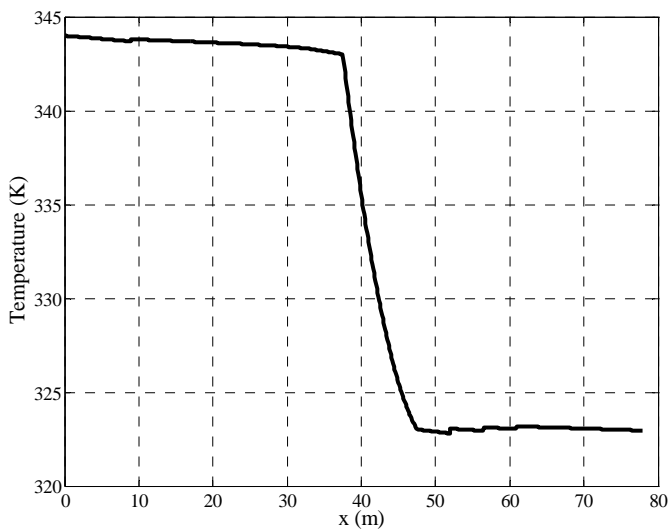

Figure 16- Temperature distribution for the longest direction of hot water in station in $T_{\text {env }}=-5^{\circ} \mathrm{C}$

\section{ECONIMICAL CONSIDERATION}

Gas heaters and inline heaters are considered by EFOM12C MARK I model. In this model, whole cost of the project during their economical life are added together and they are discounted properly vs. starting time $[4,5]$.

Mathematical formulation is,

Cost $=\sum_{i=1}^{n} \sum_{t=1}^{m}\left(I N V_{i t}+V A R_{i t}+F I X_{i t}\right) P W F_{t}$

Where,

INV is costs of capital,

VAR is running costs like costs of fuel,

FIX is fixed operation costs,

PWF is worth of present costs.

The technical information that is used for modeling is listed in Table 6.

\begin{tabular}{|c|c|c|c|c|c|}
\hline & $\begin{array}{c}\text { Capital } \\
\text { cost }\end{array}$ & Maintenance cost & efficiency & $\begin{array}{c}\text { Life } \\
\text { time }\end{array}$ & $\begin{array}{c}\text { Discount } \\
\text { rate }\end{array}$ \\
\hline Unit & $\$$ & $\$ /$ year & $\%$ & year & $\%$ \\
\hline $\begin{array}{c}\text { Gas } \\
\text { heater }\end{array}$ & $\mathbf{5 5 0 0 0}$ & $\mathbf{2 5 0 0}$ & $\mathbf{6 0}$ & $\mathbf{1 5}$ & $\mathbf{2 5}$ \\
\hline $\begin{array}{c}\text { Inline } \\
\text { heater }\end{array}$ & $\mathbf{4 7 0 0 0}$ & $\mathbf{2 5 0 0}$ & $\mathbf{7 5}$ & $\mathbf{1 5}$ & $\mathbf{2 5}$ \\
\hline
\end{tabular}

Table 6- Technical information for modeling

In this modeling, the cost of electricity and gas are assumed $6 \$ / \mathrm{kW}$ and $18 \$ / \mathrm{m}^{3}$, respectively.

The results are shown in Table 7.

\begin{tabular}{|c|c|c|c|c|}
\hline & $\begin{array}{c}\text { Capital } \\
\text { amortization }\end{array}$ & $\begin{array}{c}\text { Cost of } \\
\text { energy }\end{array}$ & Total cost & $\begin{array}{c}\text { Cost of } \\
\text { heat } \\
\text { generation }\end{array}$ \\
\hline Unit & $\$ /$ year & $\$ /$ year & $\$ /$ year & $\$ / M B t u$ \\
\hline Gas heater & $\mathbf{4 5 8 3 . 3}$ & $\mathbf{3 7 1 3 4 8}$ & $\mathbf{3 8 1 9 3 1}$ & $\mathbf{8 . 7 2}$ \\
\hline Inline heater & $\mathbf{3 9 1 6 . 6}$ & $\mathbf{2 9 7 0 7 8 . 3}$ & $\mathbf{3 0 4 3 9 4 . 9}$ & $\mathbf{6 . 9 2}$ \\
\hline
\end{tabular}

Table 7- Results of calculation

on the basis of international energy cost

Therefore, inline heaters are more appropriate than gas heaters, economically.

\section{CONCLUSION}

Comparing the second-law efficiencies of different parts of heater shows that the main reason of low value of water bath gas heaters' efficiency is the loss of huge availability during the heat transfer in water storage and gas coils.

The irreversibility is high in water-storage control volume because of the huge variation of temperatures in interface boundaries of gas coils and combustion chamber. 
On the other side, the huge amount of availability generated by gas combustion make just a little increase in availability of the gas passing the coils plunged in water and it leads to loss of exergy in coils and decrease of total efficiency of heater as well. Therefore, it is better to find appropriate replacement for gas heater with higher efficiency.

Comparing between two types of heaters that can be employed for increasing natural gas temperature were performed by utilizing one dimensional simulation and economical software EFOM-12C MARK I . In both stations, heat transfer to natural gas is approximately equal; however, shell and tube heat exchangers have higher efficiency than water bath gas heaters. Therefore, pressure reducing station with inline heaters has less energy consumption.

In order to direct installations of inline heaters system, coming and going of pipelines are not necessary and it leads to reduce piping and insulation cost and temperature drop of natural gas in the pipelines. Also, in the gas heaters, natural gas coils is adjacent to hot gases of combustion; therefore, if natural gas coil or fire tube of hot gases are damaged, explosion may be occurred. While, in the inline heaters, natural gas has contact with hot water only and it will be safer. moreover, Circuit of water circulation is closed and water evaporation is negligible; thus, inline heaters system need less water in the long period of time and it is suitable for dry environment. Also, installation and maintenance of hot water boilers and shell and tube heat exchangers are simpler.

Finally, according to energy consumption, cost and safety, inline heaters are more appropriate to increase natural gas temperature in the pressure reducing stations of natural gas.

\section{ACKNOWLEDGMENTS}

The authors acknowledge the financial support from National Iranian Gas Company (NIGC) Research and Development Center. Mr. A.A. Rezaei and Mr. Malekian are gratefully appreciated for helpful discussions.

\section{REFERENCES}

[1] Sonntag, R. E., Borgnakke, C., Van Wylen, G. J., 2000, "Fundamentals of Thermodynamics", fifth edition, Nama publication, Iran

[2] Incropera, F. P., Dewitt, D. P., 1999, "Introduction to heat transfer", third edition, Isfahan university publication, Iran.

[3] Rohsenow, W. M., Hartnett, J. P., Ganic, E. N., 1985, "Handbook of Heat Transfer Applications", McGraw-Hill, New York.

[4] 1995, "Computer tools for comparative assessment of electricity generation options and strategies", IAEA, Vienna, Austria.

[5] 1995, "Guide book on energy environment planning in developing countries; Training material on energy environment studies in Asia", Part III, United Nations, New York.

[6] Bejan, A., 1994, "Entropy generation through Heat and Fluid Flow", John Wiley \& Sons.

[7] Bejan, A., 1989,"Advanced Engineering Thermodynamics", John Wiley \& Sons.

[8] Hewitt, G. F., Shires, G. L., Polezhaev, Y. V., 1997, "International Encyclopedia of Heat and Mass Transfer", CRC Press.

[9] Kreith, F., 2000, "The CRC handbook of Thermal Engineering", CRC Press.

[10] Ludwig, E. E., 1977, "Applied Process Design for Chemical and Petrochemical Plants", Volume 3, Second Edition, Gulf Publishing Company.

[11] Weast, R. C., 1973, "Handbook of Chemistry and Physics", A Ready - Reference Book of Chemical and Physics Data, CRC Press.

[12] Perry, R. H., Green, D., Maloney, J. O., 1997, "Perry’s Chemical Engineers' Handbook", Seventh Edition, McGraw Hill.

[13] Moran, M. J., 1989, "Availability Analysis", ASME Press.

[14] Hemptinne J. C., Dhima, A., Zhou, H., 1998, "The Importance of water-hydrocarbon phase equilibrium during reservoir production and drilling operations", Institut français du pétrole. 